\title{
Pistas prosódicas na aquisição e no processamento do PB
}

Trabalho desenvolvido no âmbito de projetos de pesquisa apoiados pelo CNPq (Processo no. 401510/2010-7) e pela FAPEMIG (Processo no. SHA APQ 01911/10).

\section{Carolina Garcia de C. Silva} Doutoranda em Linguística. Programa de PósGraduação em Linguística, Universidade Federal de Juiz de Fora, Brasil.

carolinagcs@hotmail.com

\section{Vanessa Cristina de Araújo}

Doutoranda em Linguística. Programa de PósGraduação em Linguística, Universidade Federal de Juiz de Fora, Brasil.

vanessa.ufjf@gmail.com.

Resumo: Investiga-se, de modo integrado, o papel da prosódia na aquisição da linguagem e no processamento adulto. Assumindo a hipótese do Bootstrapping Fonológico (MORGAN \& DEMUTH, 1996; CHRISTOPHE et al. 1997) e a Fonologia Prosódica (NESPOR \& VOGEL, 1986), desenvolveram-se três experimentos focalizando 0 processamento adulto de sentenças Garden Path (Exp. 1) e de estruturas de Tópico e de SVO (Exp. 2), e a aquisição do adjetivo por crianças de 2-3 anos. Em conjunto, os resultados sugerem que a prosódia é fonte robusta de informação tanto para o processamento linguístico de brasileiros adultos quanto para a aquisição lexical por crianças brasileiras.

Palavras-chave: Bootstrapping Fonológico; interface prosódia-sintaxe; aquisição lexical; processamento de sentenças

\section{Azussa Matsuoka}

Doutora em Linguística. Prefeitura Municipal de Juiz de Fora. Brasil. azussam@yahoo.com.br

\section{Maria Cristina Lobo Name}

Doutora em Letras. Universidade Federal de Juiz de Fora, Brasil.

cristina.name@ufjf

Abstract: We investigate the role of prosody in language acquisition as well as adult language processing in an integrative way. Based on Phonological Bootstrapping hypothesis (MORGAN \& DEMUTH, 1996; CHRISTOPHE et al. 1997) and Prosodic Phonology Theory (NESPOR \& VOGEL, 1986), we prepared three experiments focusing on adult speech processing of Garden Path (Exp. 1) and SVO and Topic (Exp.2) sentences. We also tested 2 and 3-year-old Brazilian children acquiring new adjectives. Taken together, the results suggest that prosody is a powerful cue for both Brazilian adult language processing and Brazilian children lexical acquisition.

Key-words: Phonological Bootstrapping; prosodysyntax interface; lexical acquisition; sentence processing 



\section{Introdução}

Na Psicolinguística, vários são os trabalhos que têm investigado o papel da prosódia na aquisição da linguagem e no processamento adulto. No que se refere à aquisição de primeira língua, as pesquisas apontam para uma sensibilidade precoce do bebê a fronteiras prosódicas que delimitam orações aos quatro meses e meio (HIRSHPASEK et al., 1987; JUSCZYK et al., 1992), sintagmas aos nove meses (KEMLER-NELSON et al., 1989; GERKEN, JUSCZYK \& MANDEL, 1994) e palavras entre sete e onze meses (JUSCZYK et al., 1999; MYERS et al., 1996). No que concerne ao processamento adulto, boa parte da pesquisa se desenvolveu na área de processamento sintático, influenciada pela discussão acerca da autonomia ou não do parser i.e., se o analisador sintático humano usaria apenas informação sintática inicialmente ou teria acesso, simultaneamente, a informações de outra natureza, como semântica e prosódica. Ainda que a questão esteja longe de ser resolvida, é importante ressaltar que evidências experimentais sugerem fortemente o uso de pistas prosódicas pelo ouvinte nativo na análise de sentenças temporariamente ambíguas (SILVA, 2009; SILVA \& NAME, 2012; FONSECA, 2012) e no reconhecimento de palavras no fluxo contínuo de fala (ALVES, 2010).

No entanto, de modo geral, as pesquisas têm se desenvolvido de maneira dissociada nessas áreas. ${ }^{2}$ Nosso trabalho busca investigar, de modo integrado, o papel da prosódia tanto na aquisição da linguagem quanto no processamento adulto, assumindo a hipótese do Bootstrapping Fonológico (MORGAN \& DEMUTH, 1996; CHRISTOPHE et al. 1997). Segundo essa hipótese, o processo de aquisição de uma língua pelo bebê seria desencadeado - bootstrapped - a partir de sua análise prosódica/fonológica dos enunciados, de modo que elementos prosódicos seriam tomados como pistas de propriedades sintáticas de sua língua. O
${ }^{1}$ Ver Maia \& Finger (2005), para uma apresentação didática do assunto.

${ }^{2}$ Como exceção, temos, p.ex., o trabalho desenvolvido por Christophe e colaboradores (CHRISTOPHE ET AL., 1997; 2003; 2004; GOUT, CHRISTOPHE \& MORGAN, 2004, entre outros). 
desencadeamento da aquisição sintática, via prosódia, alavancaria, por sua vez, a aquisição lexical. Esse modelo vai além, defendendo que os recursos cognitivos disponíveis ao bebê para o tratamento acústico dos enunciados também seriam usados pelos adultos, em um processo contínuo e permanente.

A hipótese do Bootstrapping Fonológico pressupõe que a fala é organizada hierarquicamente em constituintes prosódicos e que o envelope prosódico seria sensível à sua estrutura sintática, tal como proposto pela Fonologia Prosódica (NESPOR \& VOGEL, 1986). Tal teoria estabelece que a fala se organiza em níveis prosódicos hierarquicamente dispostos em uma estrutura arbórea de domínios - um nível superior se formando a partir do(s) constituinte(s) do nível imediatamente mais baixo em um total de sete domínios. O menor constituinte é a sílaba e o maior o enunciado fonológico. Os dois níveis que possibilitariam a interface entre os níveis prosódico e sintático são o sintagma fonológico $(\varphi)$ e o sintagma entoacional (I), uma vez que as fronteiras desses constituintes prosódicos coincidem com fronteiras sintáticas.

É justamente essa interface sintaxe-prosódia que é explorada nos experimentos de processamento sintático com adultos. Dentre outros pesquisadores, Kjelgaard e Speer (1999) e DeDe (2010), no inglês, e Fonseca (2012), no português, investigaram as influências de fronteiras de sintagmas entoacionais (I) na análise sintática inicial de sentenças com ambiguidades estruturais temporárias. Esses trabalhos examinam o papel da prosódia em sentenças Garden Path clássicas, nas quais o parser, quando se depara com uma interpretação equivocada durante o processamento sintático, deve reanalisar a sentença ou um determinado ponto crítico, a fim de seguir outra interpretação (FRAZIER \& FODOR, 1978). Os resultados obtidos sugerem que as pistas prosódicas impediriam o efeito Garden Path. 
Além das pistas de sintagma entoacional, também há evidências de que pistas de sintagma fonológico são usadas pelos ouvintes no processamento sintático. Millote et al. (2007), no francês, e Silva (2009), bem como Silva \& Name (2012), no português, observaram que adultos exploraram a posição da fronteira de sintagma fonológico na tarefa de distinção de palavras ambíguas (verbos ou adjetivos), sugerindo que a identificação da categoria lexical da palavra alvo foi facilitada pela prosódia.

Com vistas a buscar evidências de que adultos falantes nativos do português brasileiro (doravante, $\mathrm{PB}$ ) usam propriedades prosódicas da fala como pistas no processamento sintático, realizamos duas atividades experimentais. A primeira trata de sentenças Garden Path e busca replicar resultados encontrados na literatura. São apresentadas sentenças com ambiguidade sintática temporária, em que um elemento crítico (Enquanto a mulher acordava os filhos faziam seu café) pode ser tomado provisoriamente como objeto direto do verbo da oração relativa, mas é o sujeito da oração principal. O segundo experimento avalia se o contorno prosódico sinalizaria ao ouvinte, desde o início, o tipo de estrutura sintática em curso: de tópico ( $A$ menina limpa o cachorro sujou ela todinha) ou SVO ( $A$ menina limpa o cachorro com xampu especial).

Para verificar se crianças brasileiras adquirindo o PB exploram propriedades prosódicas dos enunciados, investigamos a aquisição de novos adjetivos por crianças de dois a três anos. Escolhemos o adjetivo por apresentar alguns desafios para sua aquisição: não possuem, necessariamente, marca morfológica específica de categoria (morfema adjetival), podendo ser semelhantes, fonicamente, a nomes; podem se apresentar antes ou depois do nome, ainda que haja uma ordem preferencial no PB (N-ADJ), e podem aparecer na posição estruturalmente reservada a um nome (p.ex., "pega o amarelo..."). 
Na próxima seção, apresentaremos os experimentos realizados com adultos (seção 1) e, em seguida, os experimentos com crianças em processo de aquisição (seção 2). Nas considerações finais, procuraremos mostrar como o conjunto das evidências encontradas é relevante para o estudo do papel da prosódia na aquisição e no processamento do $\mathrm{PB}$.

\section{Processamento adulto}

Para investigar o papel da prosódia no curso do processamento sintático, foram realizados dois experimentos com adultos falantes do PB com a técnica de escuta automonitorada. Nessa técnica, as sentenças gravadas são cortadas em partes e o ouvinte controla o tempo de escuta de cada parte, apertando uma tecla. Para isso, foi utilizado o software PsyScope (COHEN et al., 1993; MACWHITNNEY et al., 1997) que, além de apresentar os estímulos de modo aleatório, registra o tempo de escuta de cada parte das sentenças. O primeiro experimento trata da influência de pistas de fronteiras de sintagma entoacional no processamento de sentenças Garden Path. Já o segundo focaliza o papel de fronteiras prosódicas em dois tipos de estruturas sintáticas - SVO e Tópico.

\subsection{0 processamento de sentenças Garden Path com contorno prosódico}

As sentenças Garden Path são conhecidas na literatura por conterem uma ambiguidade sintática temporária, como em: "Enquanto a mulher acordava os filhos faziam seu café", em que "os filhos” possuem, inicialmente, uma dupla possibilidade de interpretação. A teoria do Garden Path teve seu início a partir dos trabalhos de Frazier (FRAZIER \& FODOR, 1978; FRAZIER, 1979) que identificaram um efeito de reanálise 
sintática, observado por meio de atividades experimentais na modalidade escrita. Estudos recentes têm sugerido que falantes/ouvintes do português (brasileiro e europeu) fazem uso de pistas prosódicas na produção e são sensíveis a essas na interpretação das sentenças com a ambiguidade estrutural em estudo (FONSECA, 2012). Nesse sentido, a fim de encontrar evidências empíricas do papel da prosódia no processamento de sentenças Garden Path, diferindo do trabalho de Fonseca (2012) no que diz respeito à abordagem teórico-metodológica utilizada, foi realizada, com base no trabalho de Gayle Dede (2010), a atividade experimental cuja descrição é apresentada a seguir.

Para a elaboração desse experimento foram selecionados 12 verbos com dupla transitividade e 12 verbos intransitivos (6 perfeitos - meditar, caminhar, fofocar, espirrar, cochichar, viajar - e 6 imperfeitos $^{3}$ atirar, cozinhar, protestar, relaxar, debochar, descansar). Nas frases (a), foram utilizados os verbos com dupla transitividade, seguidos de expressões plausíveis como complementos destes. Já nas frases (b), utilizou-se a mesma estrutura da frase (a), com exceção do verbo subordinado que é substituído por um verbo intransitivo e a expressão temporariamente ambígua torna-se, portanto, implausível como complemento deste.

Depois de formuladas, as sentenças de tipos (a)

${ }^{3}$ Devido à dificuldade de se elegerem 12 verbos intransitivos com os padrões silábicos desejados, optou-se por separar essa condição em dois grupos: o grupo I (intransitivos perfeitos) é composto por verbos que não admitem complementos e o grupo II (intransitivos imperfeitos), por verbos que são preferencialmente intransitivos, mas que admitem complementos em determinados usos. e (b) foram gravadas duas vezes cada por uma falante adulta do PB e, após gravadas, foram analisadas no Praat (BOERSMA \& WEENINK, 2013) a fim de verificar se os contornos prosódicos apresentavam as diferenças desejáveis. Na condição prosódia 1 (P1), os contornos prosódicos conduzem a interpretação da expressão temporariamente ambígua "os filhos", no exemplo, como sujeito do verbo principal "faziam". Na condição prosódia 2 (P2), a mesma expressão é levada a ser interpretada como objeto do verbo subordinado "caminhava" e 
"acordava", no exemplo. Apresentam-se abaixo as condições experimentais utilizadas:

\begin{tabular}{|l|l|l|}
\hline (a) & (p1) & Enquanto a mulher acordava (I) os filhos faziam seu café. \\
\hline & (p2) & Enquanto a mulher acordava os filhos (I) faziam seu café. \\
\hline \multicolumn{3}{|c|}{} \\
\hline (b) & (p1) & Enquanto a mulher caminhava (I) os filhos faziam seu café. \\
\hline & (p2) & Enquanto a mulher caminhava os filhos (I) faziam seu café. \\
\hline
\end{tabular}

As diferenças prosódicas encontradas podem ser visualizadas nas figuras abaixo. Observou-se uma pausa após o verbo da oração subordinada na condição P1 e após a expressão temporariamente ambígua na condição P2, sinalizando a existência de fronteira de sintagma entoacional nestes locais. No que diz respeito à duração, há um alongamento da sílaba tônica da expressão ambígua na condição P2 em relação ao mesmo segmento na condição P1. Por fim, a curva de pitch nos mostra uma tendência de subida de F0 antes da fronteira de sintagma entoacional no verbo subordinado e após tal fronteira na expressão ambígua e no verbo principal.

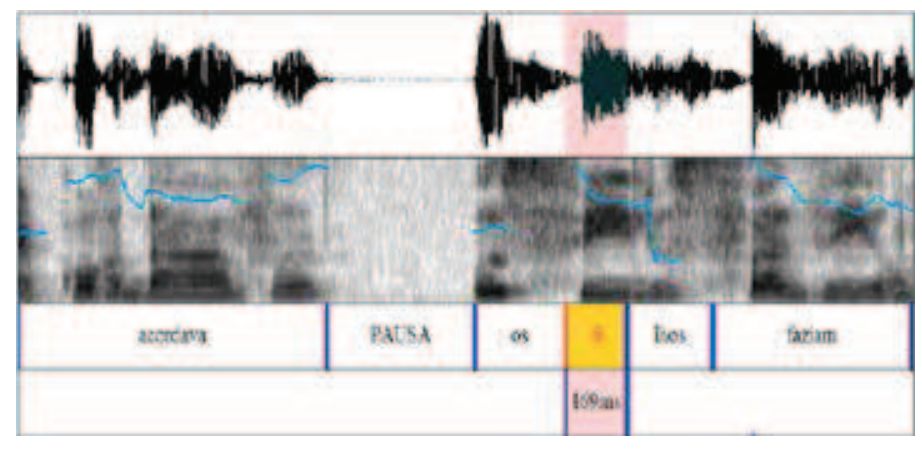




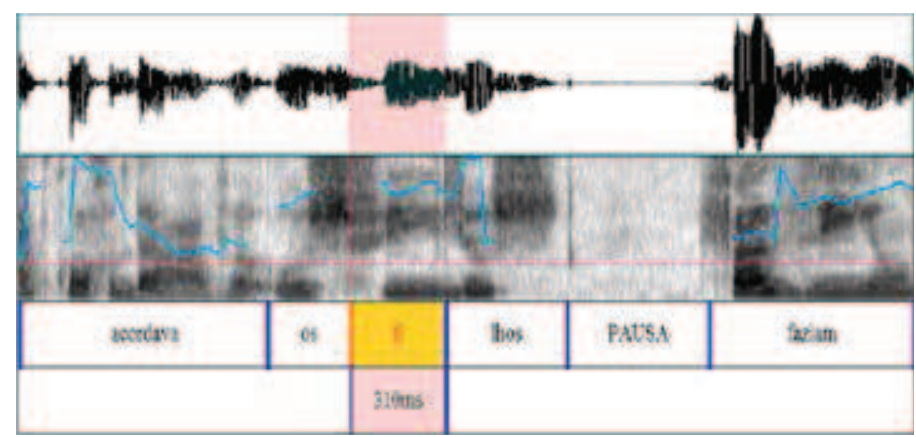

Figuras 1 e 2: forma de onda, espectograma e contorno de F0 nos três segmentos analisados da frase (a), respectivamente, nas condições P1 e P2.

Dessa maneira, a análise das pausas, bem como dos valores da duração e frequência fundamental, evidenciam a existência de um contorno melódico próprio que definiria a fronteira de sintagma entoacional. Procuramos, assim, investigar através de uma atividade experimental se os ouvintes seriam sensíveis a essas pistas prosódicas.

As frases gravadas e analisadas foram, então, cortadas, com o uso do programa Praat, em cinco partes, conforme ilustram as barras nos exemplos a seguir:

(a) Enquanto a mulher/ acordava/ os filhos/ faziam/ seu café.

(b) Enquanto a mulher/ caminhava/ os filhos/ faziam/ seu café.

Os pontos críticos analisados, em itálico nos exemplos acima, foram: (i) o verbo principal para as frases (a), uma vez que nesse ponto o ouvinte percebe se os contornos prosódicos o fizeram realizar uma análise anômala na condição P2, levando-o ao efeito GardenPath; (ii) a expressão ambígua nas frases (b), momento em que o ouvinte percebe que a prosódia estaria indicando uma interpretação não licenciada sintaticamente em P2. 
Hipótese: As pistas prosódicas, mais especificamente a fronteira de sintagma entoacional, facilitam a desambiguização das sentenças com ambiguidade estrutural temporária em estudo.

\section{Previsões:}

i. Nas frases (a), haverá um tempo de resposta maior no segundo verbo, na condição P2 em relação à condição $\mathrm{P} 1$, refletindo a reanálise.

ii. Nas frases (b), haverá um tempo maior de resposta na expressão temporariamente ambígua na condição $\mathrm{P} 2$ em relação à condição $\mathrm{P} 1$, refletindo um estranhamento por parte do ouvinte.

Material: 12 pares de sentenças, gravadas duas vezes cada, gerando, portanto, 48 sentenças testes e quatro condições experimentais.

Variáveis: dependente - tempo de escuta; independentes - tipo de estrutura sintática e tipo de envelope prosódico (design 2x2).

Procedimento: cada sujeito participou da atividade individualmente em uma sala silenciosa. Primeiramente, o experimentador passou as instruções e fez um treinamento a fim de que o participante entendesse bem o funcionamento da tarefa. Depois o participante ficou sozinho na sala durante toda a execução do experimento. O procedimento, que durou em média 20 minutos, seguiu os seguintes passos: o participante apertava uma tecla pra iniciar. Antes do início de cada frase, aparecia no centro da tela uma cruz para que o participante pudesse focalizar a atenção. Para ouvir cada parte das frases, apertava a tecla espaço. Os tempos de escuta de cada parte eram computados. Durante a escuta, a tela do computador permanecia em branco e, após ouvir a frase toda, aparecia no centro da tela uma pergunta, para garantir a atenção do 
ouvinte, à qual o participante respondia sim (apertando a tecla azul) ou não (apertando a tecla vermelha). Em seguida, aparecia novamente a cruz no centro da tela para que iniciasse uma nova frase.

Sujeitos: 36 falantes adultos (11 homens e 25 mulheres).

\section{Resultados e discussão}

De acordo com o previsto, houve uma diferença significativa entre as condições (P1) e (P2) para as frases (a):

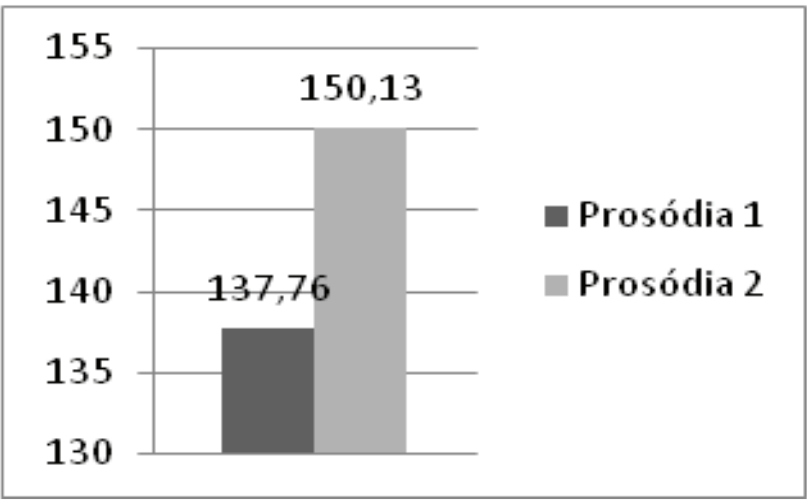

Gráfico 1: Média dos tempos de resposta do verbo da oração principal das frases (a) nas condições P1 e P2.

Os resultados revelaram uma diferença de $123,75 \mathrm{~ms}$ entre as médias dos tempos de resposta no verbo da oração principal das frases (a) de cada condição (P1 e P2). Essa diferença revelou-se estatisticamente significativa $(\mathrm{t}(35)=2.45 ; \mathrm{p}<.02)$.

Os resultados das frases (b) foram separados em 2 grupos - Grupo I (intransitivos perfeitos"); Grupo II (intransitivos imperfeitos). Ao contrário do esperado, os resultados encontrados tanto para o grupo (I) quanto para o grupo (II) não foram estatisticamente significativos. 


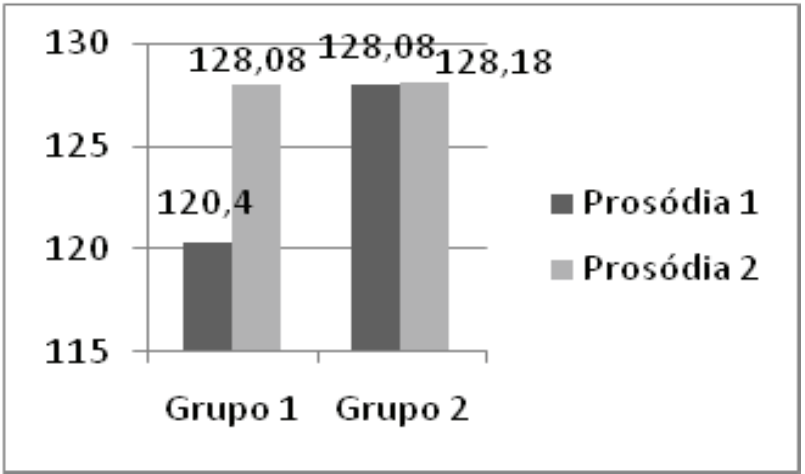

Gráfico 2: Média dos tempos de resposta da expressão ambígua das frases (b) nas condições P1 e P2.

O conjunto de resultados desse experimento sugere um papel facilitador da prosódia no processamento de sentenças temporariamente ambíguas. Nas frases (a) os sujeitos ouviram por mais tempo os verbos cujos contornos prosódicos indicavam a expressão ambígua como complemento do verbo da oração subordinada (condição P2), sugerindo a reanálise por parte do ouvinte que, ao se deparar com o verbo da oração principal, reinterpreta a expressão ambígua como sujeito deste. Nas frases (b), o conhecimento da grade argumental selecionada pelo verbo da oração subordinada, nesse caso intransitivo, parece fazer com que o ouvinte não estranhe o fato de os contornos prosódicos levarem a interpretação de um SN como complemento deste, o que causaria uma incongruência semântica.

\subsection{Pistas prosódicas para a construção da estrutura sintática}

Como vimos na atividade anterior, informação de natureza prosódica parece evitar que o ouvinte analise inadequadamente a sentença, facilitando o processamento sintático de sentenças Garden Path. No entanto, com base nos resultados das frases (b), a informação sintática (grade argumental) seria mais forte que a prosódica. 
Ainda, temos que reconhecer que sentenças desse tipo não são comuns na fala espontânea e, portanto, os resultados experimentais poderiam não estar refletindo o processamento linguístico em situações cotidianas.

A fim de investigarmos se a prosódia poderia fornecer pistas para a construção da estrutura sintática no curso do processamento, buscamos confrontar duas estruturas mais frequentes na fala espontânea e que apresentam contorno prosódico diferenciado desde o início: a estrutura de tópico ${ }^{4}$ e a estrutura SVO.

Para a realização deste experimento, selecionamos 12 palavras ambíguas, que podem pertencer tanto à categoria $\mathrm{V}$, quanto à categoria $\mathrm{ADJ}$ : dissílabas - limpa, muda, paga, salva, suja, cega; trissílabas - estranha, expulsa, liberta, oculta, segura, aceita. Foram criados pares de sentenças com os dois tipos de estruturas sintáticas:

\section{- Adjetivo - Estrutura de Tópico}

[A garota MUDA] I [a criança] $\phi$ [beijou ela] $\phi$ [com carinho.] $\phi$

\section{- Verbo - Estrutura de SVO}

[A garota] $\phi$ [MUDA a criança] $\phi$ [pr'uma escola] $\phi$ [diferente.] $\phi$

Na primeira condição (Tópico), há uma fronteira de sintagma entoacional (I) logo após a palavra ambígua; na segunda (SVO), há uma fronteira de sintagma fonológico $(\varphi)$ entre o nome e a palavra ambígua.

As sentenças foram gravadas por uma falante adulta do PB e analisadas no Praat. Foram encontradas diferenças prosódicas significativas entre os dois tipos de estrutura sintática.

Como podemos observar nas figuras abaixo, na estrutura de Tópico, encontramos uma fronteira de
${ }^{4}$ Sobre a importância e frequência de uso das construções de tópico no $\mathrm{PB}$, ver Pontes (1987), e a descrição de sua entonação, Orsini (2005). 
sintagma entoacional marcada por uma pausa longa após o Adj. Além disso, ocorre um alongamento da sílaba tônica de Adj e há um contorno melódico descendente no final do constituinte. Na estrutura de SVO, há uma fronteira entre $\mathrm{N}$ e $\mathrm{V}$, marcada por uma pausa mais curta. $\mathrm{O}$ alongamento da sílaba tônica não ocorre na palavra ambígua, mas no $\mathrm{N}$ que a antecede. Há também um contorno melódico descendente sinalizando o fechamento do constituinte.
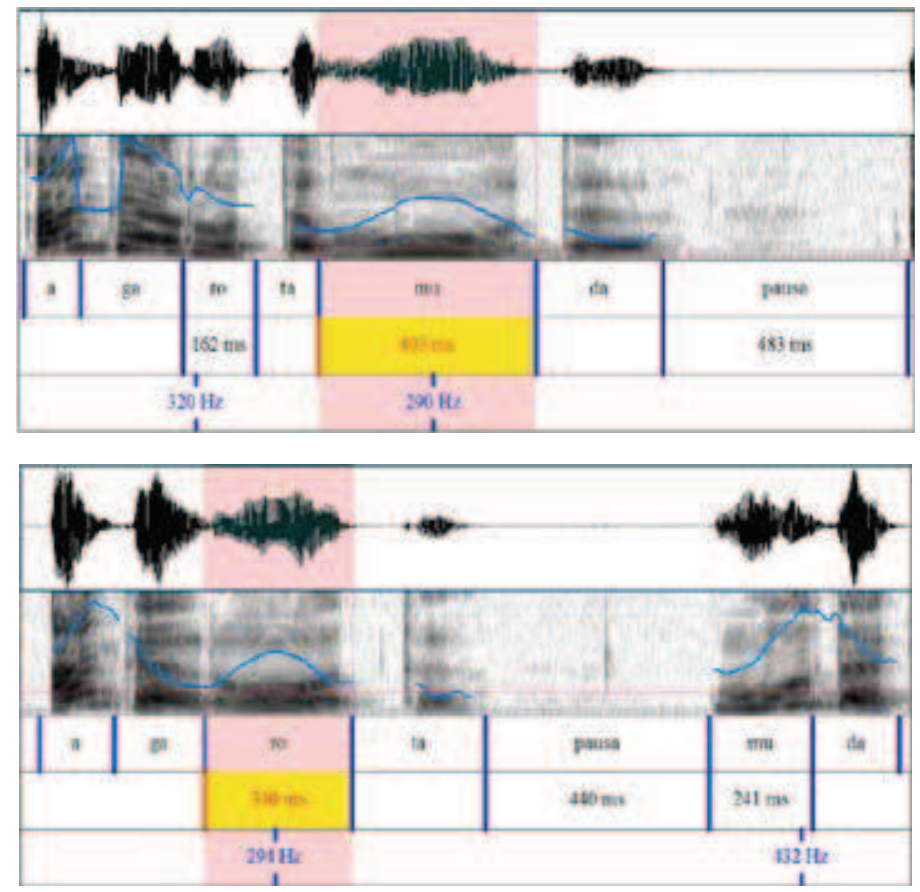

Figuras 3 e 4: forma de onda, espectrograma e contorno de F0 nas estruturas de tópico - [A garota MUDA]I e SVO - [A garota] $\phi$ [MUDA

A partir dos resultados que evidenciaram as diferenças prosódicas entre as estruturas de Tópico e de SVO, buscamos verificar através de experimento de compreensão, se os ouvintes captam essas diferentes propriedades prosódicas que sinalizam duas estruturas sintáticas distintas. 
Com o programa Praat, as sentenças gravadas foram cortadas em quatro partes. Em seguida, os arquivos de som foram combinados da seguinte maneira:

$[\text { A garota MUDA }]_{I} \longrightarrow[\text { a criança }]_{\varphi}[\text { beijou ela }]_{\varphi}[\text { com carinho }]_{\varphi}$. [A garota $] \varphi[\mathrm{MUDA} \longrightarrow \text { a criança }]_{\varphi}\left[\mathrm{pr}^{\prime} \text { uma escola }\right]_{\varphi}[\text { diferente }]_{\varphi}$.

Desse modo, foram geradas 4 condições experimentais, sendo ApSVO e VpTOP aquelas em que há incompatibilidade entre estrutura prosódica e sintática.

- ApTOP: Estrutura de Tópico (Det+N+ADJ) + Prosódia de Tópico

[A garota muda] I // [a criança] // beijou ela // com carinho.

- ApSVO: Estrutura de Tópico (Det+N+ADJ) + Prosódia de SVO

[A garota] $\varphi$ [muda // a criança] // beijou ela // com carinho.

- VpTOP: Estrutura de SVO $($ Det $+\mathrm{N}+\mathrm{V})+$ Prosódia de Tópico

[A garota muda] I// [a criança] // pr'uma escola // diferente.

- VpSVO: Estrutura de SVO $($ Det $+\mathrm{N}+\mathrm{V})+$ Prosódia de SVO

[A garota] $\varphi$ [muda // a criança] // pr'uma escola // diferente.

Cada sentença foi dividida em quatro partes (separadas por // acima). Consequentemente, tomamos como parte crítica a terceira, pois é o momento da escuta em que o ouvinte percebe se a prosódia o levou a interpretar a sentença de modo equivocado, gerando um tempo maior de escuta. 
Hipótese: o envelope prosódico pode guiar o ouvinte na escolha de uma das duas possíveis estruturas sintáticas em situação de ambiguidade.

Previsão: o ouvinte, ao se deparar com pistas prosódicas que são incongruentes em relação à sintaxe, deve reanalisar a sentença, o que aumentaria o tempo de escuta nessas condições.

Material: 12 pares de sentenças, distribuídas entre 4 grupos de participantes +36 distratoras.

Variáveis: dependente - tempo de escuta (especificamente da terceira parte de cada frase); independentes - tipo de estrutura sintática e tipo de envelope prosódico (design 2x2).

Procedimento: O mesmo procedimento utilizado no experimento anterior (tarefa de escuta automonitorada).

Sujeitos: 23 adultos (10 homens e 13 mulheres)

\section{Resultados e discussão}

Conforme o previsto, os RTs foram maiores nas duas condições em que há incompatibilidade entre as estruturas sintática e prosódica:

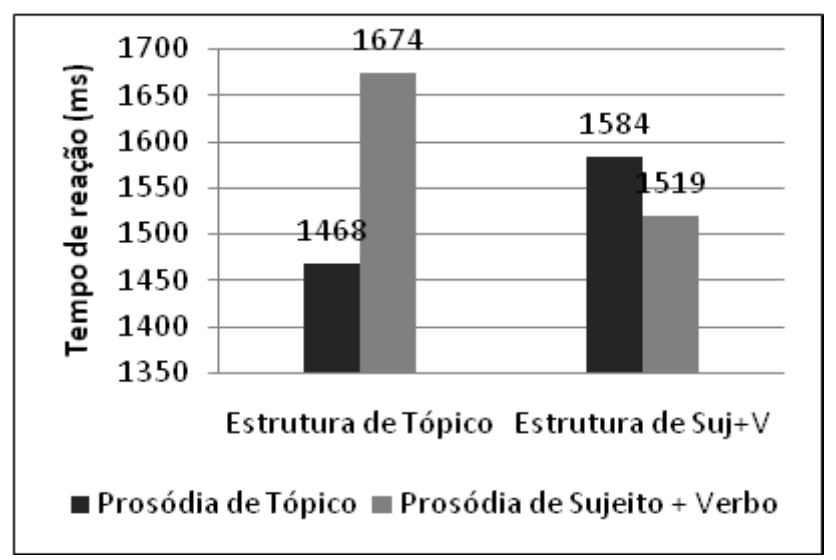

Gráfico 3: Resultados do Experimento (2) - médias dos tempos de escuta 
Houve interação entre tipo de estrutura e tipo de prosódia $-F(1,68)=4,27 p<0,042$. Foi significativo o efeito da prosódia de Tópico - ApTOP vs. VpTOP - t(68)=2,15 $\mathrm{p}<0,034$. Mas, por outro lado, o efeito da prosódia SVO foi marginal - ApSVO vs. VpSVO - $\mathrm{t}(68)=1,75 \mathrm{p}<0,084$.

Os resultados obtidos até o momento parecem indicar um efeito da prosódia quando esta é incompatível com a estrutura sintática. Tal efeito parece ser mais robusto quando a prosódia indica estrutura de Tópico do que quando sinaliza a estrutura de SVO. Quando o ouvinte se depara com uma incongruência entre o tipo de prosódia e a estrutura sintática, ocorreria um estranhamento, sendo necessária a reanálise da sentença, o que acarretaria um tempo maior de processamento.

Podemos, portanto, defender que adultos falantes nativos do PB produzem marcas prosódicas que são usadas pelos ouvintes no processamento, seja para desambiguizar estruturas potencialmente ambíguas sintaticamente, seja para construir estruturas sintáticas distintas. Mas, além dessas funções, defendemos que as propriedades prosódicas são fundamentais no processo de aquisição de uma língua, e são usadas como pistas para a aquisição sintática e lexical pela criança, como veremos na próxima seção.

\section{Aquisição Lexical}

No processo de aquisição de uma língua, em que o vocabulário tem de ser apreendido, a organização prosódica dos enunciados pode ter um papel fundamental, fornecendo pistas à criança para a segmentação do fluxo da fala (SHUKLA et al., 2007). No que se refere à aquisição de adjetivos, Thorpe \& Fernald (2006) observaram que crianças americanas de 2 anos podem integrar informação distribucional e pistas prosódicas do inglês para o mapeamento de palavras novas a adjetivos. 
No PB, Matsuoka (2007) observou que nomes e adjetivos possuem contornos prosódicos distintos dentro de um Sintagma Determinante (DP, de Determiner Phrase), e que a fala dirigida à criança (FDC) pode, em alguns aspectos, potencializar essas distinções. Assim, no presente estudo, buscamos investigar em que medida crianças de 2 e 3 anos fazem uso dessas pistas prosódicas do adjetivo no processo de aquisição lexical.

\subsection{A prosódia no mapeamento de palavras novas a adjetivos}

Este experimento tem como objetivo verificar se pistas prosódicas de adjetivos no $\mathrm{PB}$ facilitam o mapeamento de palavras novas (pseudopalavras) à categoria $\mathrm{ADJ}$ (etivo) por crianças em fase de aquisição da linguagem. Tomamos como ponto de partida os estudos de Azevedo (2008) acerca da identificação de novos adjetivos por crianças brasileiras de 2 e 3 anos. As crianças de ambas as idades tiveram mais facilidade em mapear o novo adjetivo à propriedade do objeto quando apresentado juntamente com um nome conhecido (NC). Quando essa mesma palavra foi apresentada com um nome vago (NV) seu mapeamento ficou comprometido. No entanto, diante de pseudoadjetivos com sufixos (osolosa; adol ada), as crianças não tiveram dificuldade no mapeamento tanto nas condições NC ou NV, sugerindo que as pistas morfofonológicas podem ser usadas por crianças na faixa de 2 e 3 anos na identificação de novos adjetivos.

Nossa questão é se o contorno prosódico seria uma pista tão robusta para a identificação de elementos da categoria $\mathrm{ADJ}$ quanto os morfemas parecem ter sido. Em outros termos, se, na ausência de marcador morfofonológico e apresentadas com nomes vagos, pseudopalavras prosodicamente marcadas como ADJ seriam assim reconhecidas pelas crianças. 
Hipótese: a criança de 2 e 3 anos pode, com base na informação contida no envelope prosódico do adjetivo no $\mathrm{PB}$, fazer o mapeamento de uma palavra nova à categoria $\mathrm{ADJ}$.

Previsão: Espera-se que, mesmo quando o objeto modificado pelo adjetivo for representado por um Nome Vago (NV), a informação prosódica de ADJ seja suficiente para o mapeamento congruente.

Material: Objetos confeccionados em EVA (Fig. 5) agrupados em conjuntos de 4 objetos - 2 para familiarização e 2 para teste - em quatro eventos. Cada objeto apresentava uma propriedade física que era representada por uma palavra nova em função de adjetivo (pseudoadjetivo). Para cada evento foi utilizado um pseudoadjetivo, totalizando quatro novas palavras apresentadas a cada criança.

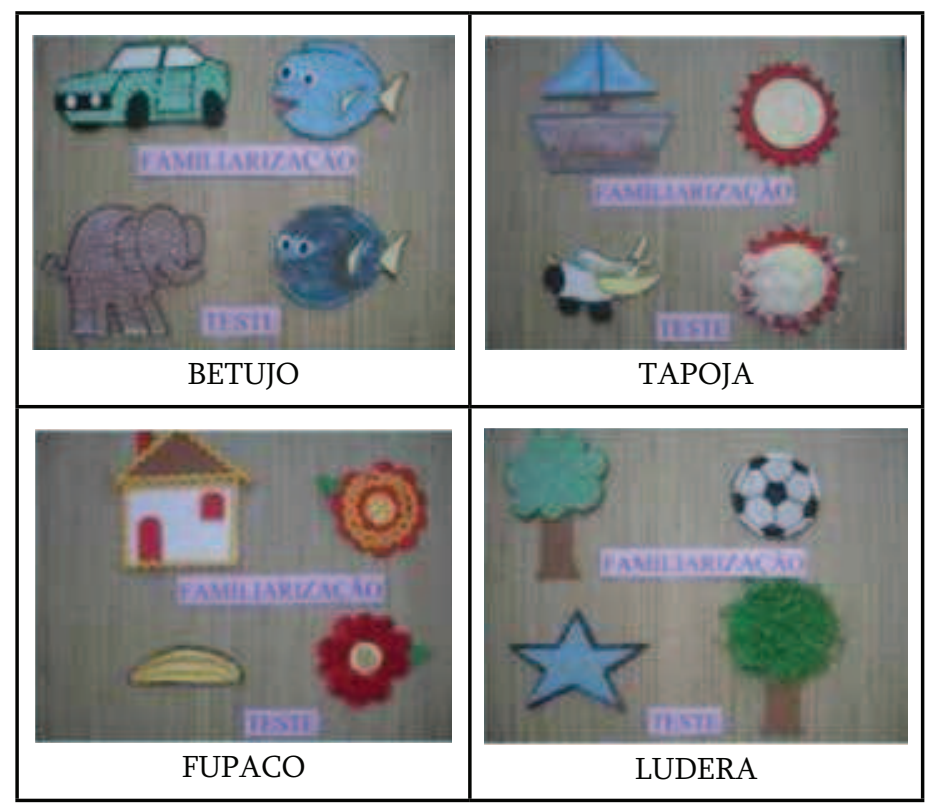

Figura 5: Objetos confeccionados em EVA utilizados para o experimento com crianças 
Procedimento: Utilizou-se a técnica de seleção de objetos. Como ilustra a Figura 5, durante a fase de familiarização, os objetos eram apresentados em agrupamentos de dois objetos de uma mesma propriedade (textura). Os objetos da familiarização eram associados a um pseudoadjetivo (betujo/tapoja/fupaco/ludera). Cada criança foi testada em apenas uma condição. Na fase de teste, a experimentadora pedia que a criança apontasse, escolhendo entre outros dois objetos (teste), aquele que se referia ao pseudoadjetivo usado na familiarização. As frases da condição prosódia realçada (PR) receberam ênfase na duração e nos contornos de pitch. A tarefa da criança era apontar, dentro do par de objetos teste, aquele que apresentava a mesma propriedade. Para tal, no teste, foram apresentados (i) um objeto do mesmo tipo apresentado anteriormente, mas com propriedade diferente; e (ii) um objeto de outro tipo com a propriedade previamente familiarizada.

\section{Condições:}

Condição 1 (NC + PC): Associação de NC sem realce prosódico à pseudopalavra em função de adjetivo. Ex: um carro betujo; um peixe betujo.

Condição 2 (NV + PC): Associação de NV sem realce prosódico à pseudopalavra em função de adjetivo. Ex: uma coisa tapoja; outra coisa tapoja.

Condição 3 (NV + PR): Associação de NV com realce prosódico à pseudopalavra em função de adjetivo. Ex: um negócio FUPACO, outro negócio FUPACO.

Variáveis: independentes: a) prosódia de ADJ (com realce prosódico x sem realce prosódico), e b) o tipo de N (Conhecido x Vago); dependente: o número de respostas congruentes conforme familiarização.

Sujeitos: Foram testadas 48 crianças - 18 crianças de 2 anos (idade média: 2,5 anos) e 18 crianças de 3 anos (idade média: 3,4 anos). 


\section{Resultados e discussão}

Os resultados das comparações par a par dos dados de mapeamento congruente das três condições são apresentados na tabela a seguir:

\begin{tabular}{|c|c|}
\hline 2 anos (idade média: 2 a e $5 \mathrm{~m}$ ) & 3 anos (idade média: 3 a e 4 m) \\
\hline $\begin{array}{l}\text { Condição } 1 \text { (NC + PC) x Condição } \\
2 \text { (NV + PC) } \\
\mathrm{z}(64)=3,585, \mathrm{p}=0,0001\end{array}$ & $\begin{array}{l}\text { Condição } 1 \text { (NC + PC) x Condição } \\
2(\text { NV + PC) } \\
z(64)=2,611, p=0,009\end{array}$ \\
\hline $\begin{array}{l}\text { Condição } 1(\mathrm{NC}+\mathrm{PC}) \times \text { Condição } \\
3 \text { (NV + PR) } \\
\mathrm{z}(64) 0,925, \mathrm{p}=0,35\end{array}$ & $\begin{array}{l}\text { Condição } 1 \text { (NC + PC) x Condição } \\
3 \text { (NV + PR) } \\
z(64)=0,683, p=0,683\end{array}$ \\
\hline $\begin{array}{l}\text { Condição } 2 \text { (NV + PC) x Condição } \\
3 \text { (NV + PR) } \\
\mathrm{z}(64)=2,762, \mathrm{p}=0,005\end{array}$ & $\begin{array}{l}\text { Condição } 2(\mathrm{NV}+\mathrm{PC}) \text { x Condição } \\
3 \text { (NV + PR) } \\
\mathrm{z}(64) 3,211, \mathrm{p}=0,001\end{array}$ \\
\hline
\end{tabular}

Tabela 1: Resultado do teste Mann-Whitney comparando o mapeamento consistente de pseudopalavra à propriedade nas condições 1 , 2 e 3.

Observamos que, comparadas as condições 1 e 2 (apresentação da palavra nova juntamente com nomeação do objeto vs. nome vago sem realce prosódico), a diferença é significativa. Por outro lado, na comparação da condição 1 (objeto nomeado) com a condição 3 (palavra nova associada a nome vago, com realce prosódico de ADJ) a diferença não foi significativa. Esse dado sugere que a pista prosódica teve o mesmo efeito da pista de nomeação do objeto para o mapeamento congruente. A comparação das condições 2 e 3 compostas de nome vago (sem realce prosódico vs. com realce prosódico) apresentou diferença significativa, sugerindo que, na ausência de um elemento nomeador do objeto, a ênfase prosódica no pitch e na duração da pseudopalavra pode ser usada como informação no mapeamento consistente da palavra nova à propriedade. Não foram observadas diferenças de comportamento com relação à idade das crianças (2 e 3) anos. Os resultados sugerem que crianças de 2 e 3 anos são sensíveis ao envelope prosódico de $\mathrm{ADJ}$ no $\mathrm{PB}$ e que as 
pistas prosódicas dessa categoria podem ser utilizadas no mapeamento congruente da propriedade a uma palavra nova que a representa.

\section{Considerações finais}

Neste artigo, buscamos apresentar evidências do uso de propriedades prosódicas do PB por crianças e adultos brasileiros.

No experimento com crianças, verificamos que o uso da ênfase prosódica no ADJ facilitou a identificação da nova palavra como adjetivo, mesmo na ausência de marca morfofonológica. As propriedades prosódicas presentes na fala dirigida à criança parecem auxiliar a criança no processo de constituição do léxico, sinalizando informação categorial através do realce prosódico. Dado que a marca morfofonológica não é obrigatória para os adjetivos do $\mathrm{PB}$, informação de natureza prosódica pode ser uma fonte robusta para o reconhecimento dos elementos da categoria $\mathrm{ADJ}$ no processo de aquisição dessa língua.

Também observamos que o envelope prosódico é pista relevante no processamento adulto, quando essa é a única fonte de informação disponível. Ouvintes adultos apresentaram RTs maiores em condições de prosódia incongruente com a estrutura sintática.

Em conjunto, os resultados sugerem que o envelope prosódico seria uma fonte robusta de informação tanto para o processamento linguístico adulto quanto para a aquisição lexical por crianças. Ainda, sugerem que as habilidades perceptuais e os recursos cognitivos que parecem auxiliar a criança na aquisição do léxico de uma língua (e de sua sintaxe) estariam também disponíveis ao adulto que, mesmo

já conhecendo sintaxe e léxico, faria uso dessas habilidades e recursos no processamento de sentenças. 
Acreditamos na relevância dos estudos apresentados, visto que a área de processamento prosódico é ainda muito carente de literatura específica para o PB. Os resultados obtidos até o momento reforçam a hipótese de que a sensibilidade de crianças/bebês à prosódia de sua língua pode se constituir como porta de entrada no processo de aquisição lexical e sintática de sua língua, e que o seu efeito pode ser observado no processamento adulto. 


\section{Referências}

ALVES, D. Pistas prosódicas no acesso lexical on-line de falantes adultos do português brasileiro. Dissertação de Mestrado. Universidade Federal de Juiz de Fora, 2010.

AZEVEDO, L. O. F. Uma flor tapoja e uma casa jufosa: o papel da nomeação e de propriedades morfofonológicas no processo identificação de novos adjetivos por crianças brasileiras. Dissertação de Mestrado. Universidade Federal de Juiz de Fora, 2008.

BOERSMA, P.; WEENICK, D. PRAAT: doing phonetics by computer (version: 5.3.53), 2013. Disponível em: http://www. praat.org/.

CHRISTOPHE, A.; GUASTI, T.; NESPOR, M.; DUPOUX, E.; OOYEN, B.V. Reflexions on phonological bootstrapping: its role for lexical and syntactic acquisition. Language and Cognitive Processes, 12(5/6), 1997. p. 585-612.

CHRISTOPHE A.; NESPOR, M.; GUASTI, M. T.; OOYEN, B. V. Prosodic structure and syntactic acquisition: the case of the head-direction parameter. Developmental Science, 6(2), 2003. p. 213-222.

CHRISTOPHE, A.; PEPERKAMP, S.; PALLIER, C.; BLOCK, E. e MEHLER, J. Phonological phrase boundaries constrain lexical access - I. Adult data. Journal of Memory and Language, 51, 2004. p. 523-547.

COHEN, J.; MACWHINNEY, B.; FLATT, M., PROVOST, J. PsyScope: An interactive graphic system for designing and controlling experiments in the psychology laboratory using Macintosh computers. Behavior Research Methods, Instruments, and Computers, 25(2), 1993. p. 257-271. 
DEDE, G. Utilization of Prosodic Information in Syntactic Ambiguity Resolution. Journal Psycholinguist Research, 39, 2010. p. 345-374.

FONSECA, A. A prosódia no parsing: evidências experimentais do acesso à informação prosódica no input linguístico. Tese de Doutorado. Universidade Federal de Minas Gerais, Belo Horizonte, 2012.

FRAZIER, L. On comprehending sentences: Syntactic parsing strategies. PhD dissertation, University of Connecticut, 1979.

FRAZIER, L.; FODOR, J. D. The sausage machine: A new two-stage parsing model. Cognition, 6, 1978. p. 291-325.

GERKEN, L.A.; JUSCZYK, P.W.; MANDEL, D.R. When prosody fails to cue syntactic structure: Nine-montholds sensitivity to phonological vs. syntactic phrases. Cognition, 51, 1994. p. 237-265.

GOUT, A.; CHRISTOPHE, A; MORGAN, J. L. Phonological phrase boundaries constrain lexical access - II. Infant data. Journal of Memory and Language, 5, 2004. p. 547-567.

HIRSH-PASEK, K.; KEMLER-NELSON, D. G.; JUSCZYK, P.W.; WRIGHT-CASSIDY, K.; DRUSS, B.; KENNEDY, L. Clauses are perceptual units for young infants. Cognition, 26, 1987. p. 269-286.

JUSCZYK, P. W.; HOUSTON, D. M.; NEWSOME, M. The beginnings of word segmentation in english-learning infants. Cognitive Psychology, 39, 1999. p. 159-207.

JUSCZYK, P. W.; KEMLER-NELSON, D. G.; HIRSH-PASEK, K.; KENNEDY, L.; WOODWARD, A.; PIWOZ, J. Perception of acoustic correlates of major phrasal units by young infants. Cognitive Psychology, 24, 1992. p. 252-293. 
KEMLER-NELSON, D. G.; HIRSH-PASEK, K.; JUSCZYK, P. W.; WRIGHT-CASSIDY, K. How prosodic cues in motherese might assist language learning. Journal of Child Language, 16, 1989. p. 55-68.

KJELGAARD, M. M., \& SPEER, S. R. Prosodic facilitation and interference in the resolution of temporary syntactic closure ambiguity. Journal of Memory and Language, 40. 1999. p. 153-194.

MAIA, M.; FINGER, I. Processamento da Linguagem. Pelotas: EDUCAT, 2005.

MACWHINNEY, B.; COHEN, J.; PROVOST, J. The PsyScope experiment-building system. Spatial Vision, 11 (1) 1997. p. 99-101.

MATSUOKA, A. A marcação prosódica da posição do adjetivo no DP na fala dirigida à criança. Dissertação de Mestrado em Letras. Universidade Federal de Juiz de Fora, 2007.

MILLOTTE, S.; WALES, R.; CHRISTOPHE, A. Phrasal prosody disambiguates syntax. Language and Cognitive Processes, 22, 6, 2007. p. 898-909.

MORGAN, J. L.; DEMUTH, K. Signal to syntax: an overview. In: MORGAN, J. L. \& DEMUTH, K. (eds) Signal to Syntax: bootstrapping form speech to grammar in early acquisition. Mahawah, NJ: Lawrence Erlbaum Associates, 1996. p. 1-21.

MYERS, J.; JUSCZYK, P. W.; KEMLER-NELSON, D. G.; CHARLES-LUCE, J.; WOODWARD, A. L.; HIRSCH-PASEK, $\mathrm{K}$. Infants' sensitivity to word boundaries in fluent speech. Journal of Child Language, 23(1), 1996. p. 1-30.

NESPOR, M.; \& VOGEL, I. Prosodic phonology. Dordrecht: Foris Publications, 1986. 
ORSINI, M. T. Análise entonacional das construções de tópico. Anais do IX Congresso Nacional de Linguística e Filologia. Agosto de 2005. Disponível em: <<http://www. filologia.org.br/ixcnlf/17/06.htm>>

PONTES, Eunice. O tópico no português do Brasil. Campinas: Pontes, 1987.

SHUKLA, M.; NESPOR, M. \& MEHLER, J. An interaction between prosody and statistics in the segmentation of fluent speech. Cognitive Psychology 54, 2007, p.1-32

SILVA, C. G. C. O papel da fronteiras de sintagma fonológico na restrição do processamento sintático e na delimitação das categorias lexicais. Dissertação de Mestrado, Universidade Federal de Juiz de Fora, 2009.

SILVA, C. G. C.; NAME, M.C. "Limpa" é verbo ou adjetivo? O papel de fronteiras de sintagma fonológico no parsing. Journal of Speech Sciences, 1 (1), jan. 2012. Disponível em: http://www.journalofspeechsciences.org/index.php/ journalofspeechsciences/article/view/17.

THORPE, K; FERNALD, A. Knowing what a novel word is not: two years old "listen through" ambiguous adjectives in fluent speech. Cognition. 100, 2006. p. 389-433.

[Recebido em 30 de junho de 2013

e aceito para publicação em 10 de novembro de 2013] 